\title{
Money Growth, Inflation, and Causality (Empirical Evidence for Pakistan, 1973-1985)
}

\author{
JONATHAN D. JONES and NASIR M. KHILJI*
}

\begin{abstract}
This paper uses the Granger direct test to evaluate the causal relationship between growth in money supply and inflation in Pakistan. The historical period investigated extends from 1973 to 1985 . The results of the test show that money growth had a significant impact on inflation during the period considered. In addition, there is some evidence at hand showing that inflation, too, affected money growth over the 1973-1985 period.
\end{abstract}

\section{INTRODUCTION}

The empirical issue of the impact of money supply on rate of inflation continues to be a much debated topic. For example, Turnovsky and Wohar (1984) do not find any identifiable relationship between money supply and prices over the 1929-1978 period in the U.S., while Benderly and Zwick (1985) find money supply affecting prices in the U.S. over the 1955-1982 period. Jones and Uri (1986) also find evidence of money supply influencing price level in the U.S. during the 1953-1984 period. Studies for other countries, e.g. Driscoll, Ford, and Mullineux (1985) for the U.K., invariably report similat conflicting results about the relationship between money supply and prices.

While there are numerous empirical studies that have examined the causal relationship between money supply and prices in developed countries, there are also several recent studies that have addressed this particular issue for developing countries. In one such study, Aghevli and Khan (1978) use the Haugh-Pierce test to investigate the causal relationship between money growth and inflation in Brazil, Colombia, the Dominican Republic, and Thailand. ${ }^{1}$ The results of the tests show a feedback or bidirectional causality between money and inflation in all the four developing countries over the 1964-1974 period. In this paper, we use the Granger direct test to examine the causal relationship between changes in money supply $\left(M_{1}\right.$

*The authors are Assistant Professors, Department of Economics and Business, Catholic University of America, Washington, D.C. This paper was presented at the Eastern Economic Association Meeting, Philadelphia, PA, April 10, 1986.

${ }^{1}$ While technically only a test of time-series independence, the Haugh-Pierce test can be used to assess the causal flow between two time-series variables. 
and $\left.M_{2}\right)$ and changes in price level $(C P I$ and $W P I)$ for Pakistan over the period from 1973 to 1985

Pakistan is a country which is still in the early stages of economic development. Whether or not a causal relationship exists between money and prices in Pakistan is an important empirical issue that has remained unexplored. Most formulations of the price level that appear in various econometric models of Pakistan's economy are based on the assumption that money supply has a significant positive impact on prices. For example, in the PIDE (Pakistan Institute of Development Economics) macro-econometric model of Pakistan's economy, the structural equation for price level in the monetary block of the model is specified with money affecting prices, although no attempt has been made to verify the correctness of this specification by explicitly testing the existence of any such causal relationship from money to prices: see, for example, Khilji (1982) and Naqvi et al. (1983).

The present paper represents an initial attempt to determine whether an identifiable causal relationship exists between changes in money supply and price-level movements in Pakistan. The results of the causality test undertaken here will be of importance for a couple of reasons. Firstly, the results concerning the nature of the causal relationship between money and prices will provide information which could prove to be helpful in constructing macro-econometric models of the Pakistani economy. In other words, the causality tests undertaken here will offer insights in to the temporal relationship between money and prices which could be important in specifying appropriate linkages between money and prices in the monetary block of an econometric model.

Secondly, the results of the causality test can provide useful information to policy-makers. It is well known that causality tests can be extremely useful in isolating those variables or instruments which policy-makers can control in order to obtain desired values for target variables such as GNP, unemployment, and the rate of price change. If it turns out to be the case that money has significant explanatory power for prices (i.e. causes prices), without a feedback from prices to money, this would represent an important relationship that policy-makers may conceivably exploit in attempting to control the rate of inflation in Pakistan. This matter must be viewed in the light of the Lucas critique, according to which the ability of policy-makers to exploit the relationship would be dependent upon whether or not the underlying relationship between money and prices remained invariant to a policy intervention. According to the well-known Lucas critique of econometric models, policy changes alter the structure of econometric models with the implication that policy-maker cannot rely on discretionary policy interventions to bring about desired changes in target variables.

Before proceeding further, it would be helpful to provide some background information on Pakistan's economy. Pakistan has a mixed economy which is characterized by a significant amount of government intervention in the various sectors of the economy. For example, the farm sector, though private in nature, has had some kind of price controls imposed on major food crops, e.g. wheat and rice, since about 1956. Most inputs, such as fertilizer, pesticides, and water, are supplied by government agencies, and the supply of credit is regulated through State-owned banks. Similarly, the industrial sector has credit rationing through licensing schemes, and a significant part of the services industry (e.g. utilities, transportation, and communications industries) is State-owned.

With virtually no capital goods industry to speak of, the Pakistani economy is heavily dependent on imports of capital goods characterized by small price elasticities, suggesting that a considerable amount of inflation in Pakistan may well be imported. Government deficits have generally been financed through money expansion, and most of the empirical work to date has sought to assess the relationship between government deficits and inflation with mixed results: Naqvi et al., (1983) and Khan (1982). With regard to the recent inflationary experience of Pakistan, the 1960 s witnessed virtually no inflation, whereas the 1970 s and early 1980 s have seen the consumer price index, for example, increasing at an annual rate of about 12 percent. $^{2}$

There are several competing explanations for the significant recent increases in consumer prices. Firstly, as there was considerable world-wide inflation during the 1970 s and early 1980s, it is possible that a large part of inflation in Pakistan was imported. ${ }^{3}$ Secondly, the services sector of the Pakistani economy increased in size relative to other sectors of the economy during this recent period. It is generally assumed that the services sector is more liable to experience inflation than the commodity-producing sectors of the economy, thus leading to a higher inflation rate. Thirdly, it could be that the increases in money supply due to monetization of high government deficits have caused the prices to rise.

The remainder of the paper is organized as follows. Section II discusses the Granger direct test as well as the data used in carrying out the test. Section III presents the results of the test. Finally, Section IV offers a summary and conclusions as well as recommendations for further research.

\section{METHODOLOGICAL OVERVIEW AND DATA}

The Granger direct test is a reduced-form regression-F Wiener-Granger causality test. According to the operational definition of Wiener-Granger causality in the time

${ }^{2}$ The wholesale price index also increased at an average annual rate of 12 percent. There exists a high degree of positive correlation between the CPI and WPI in Pakistan. In addition, causality tests run initially by the authors show unidirectional causality from the CPI to WPI.

${ }^{3}$ That a part of inflation in Pakistan during the recent past was imported has received some empirical support. Causality tests initially run by the authors show import prices causing both the CPI and WPI at the 5-percent significance level over the 1973-1985 period. 
domain, one covariance stationary time series $a_{t}$ causes another covariance stationary time series $b_{t}$, if better forecasts of $b_{t}$ can be made by using the knowledge of $a_{t}$, for $t<0$, after exploiting all relevant information on past values of $b_{t}{ }^{4}$ By definition, a better forecast is one characterized by a smaller predictive-error variance.

It is well known that causal inferences yielded by the Granger test are based on F-statistics which are used to test the joint significance of particular lags associated with the independent variable in the equations estimated. In the Granger direct test, lags of the dependent variable are used as right-hand-side (RHS) variables in the equations estimated to correct serial correlation which would otherwise arise from an autocorrelated dependent variable. The importance of making an adjustment for an autocorrelated dependent variable in regression equations is well known: see, e.g., Granger and Newbold (1974). As a result of addressing the serial correlation problem in this manner, prefiltering procedures to flatten the spectral density of the regression residuals based on either time-domain or frequency-domain approaches are obviated: see Sims (1972) for a discussion of prefiltering for avoiding the serial correlation problem. Based on the findings of a recent Monte Carlo study of various alternative tests for predictive relationships between time-series variables, Geweke, Meese, and Dent (1983) recommend the use of the Granger direct test because of its desirable statistical properties.

The structure of the test is as follows. Let $\left(P_{t, t}, M_{j, t}\right)$ represent the discrete, linearly indeterministic, possibly non-stationary, bivariate information set consisting of the $i$ th inflation measure and $j$ th money-growth measure in time $t .^{5}$ The Granger direct test involves estimating the following bivariate distributed-lag model in order to examine the causal relationship between $P_{i, t}$ and $M_{j, t}$ :

$$
\begin{gathered}
{\left[\begin{array}{l}
P_{i, t} \\
M_{j, t}
\end{array}\right]=\left[\begin{array}{ll}
A^{a}(L) & B^{b}(L) \\
C^{c}(L) & D^{d}(L)
\end{array}\right]\left[\begin{array}{l}
P_{i, t} \\
M_{j, t}
\end{array}\right]+\left[\begin{array}{l}
u_{t} \\
v_{t}
\end{array}\right] \ldots \ldots} \\
\\
\\
(t=1, \ldots, T) \\
\\
(i=C P I, W P I) \\
(j=M 1, M 2)
\end{gathered}
$$

${ }^{4}$ The time series whose pairwise relationships are investigated using Wiener-Granger causality tests must be covariance or widesense stationary. By definition, a covariance stationary time-series has a constant unconditional mean and an autocovariance that is only a function of time displacement. The failure to adjust a non-stationary time-series for a trend would result in biased estimates and invalid inferences.

${ }^{5}$ Should the time series prove to be non-stationary, the non-stationarity can be removed by including a time trend in the equations estimated. where $A(L), B(L), C(L)$, and $D(L)$ are one-sided lag polynomials of order $a, b, c$, and $d$, respectively, in the lag operator $L$ with roots outside the unit circle. ${ }^{6}$ In addition, $u$ and $v$ are individually and mutually uncorrelated error processes with zero mean and constant variance. ${ }^{7}$

In order to test the presence of causality between the $i$ th inflation measure and the $j$ th money-growth measure, the following null hypotheses are tested. Under the null hypothesis that money growth does not cause price changes, $B(L)$ will be zero, while $C(L)$ will be zero under the null hypothesis that price changes do not affect money supply. Feedback or bidirectional causality exists between money and prices when both null hypotheses are rejected, whereas money and prices are not causally related when both null hypotheses are accepted. In carrying out the Granger test and drawing causal inferences, F-statistics are computed to test the joint significance of the elements in both $B(L)$ and $C(L)$.

In order to implement the Granger test, lag lengths must be chosen for the onesided lag polynomials $A(L), B(L), C(L)$, and $D(L)$, i.e. values must be assigned to $a$, $b, c$, and $d$. It should be apparent that causal inferences are sensitive to the choice of order for the lag polynomials $B(L)$ and $C(L)$ in that excessively long or excessively short lag-lengths for these one-sided lag polynomials will have an impact on the $\mathrm{F}$ statistics used in drawing inferences: see Feige and Pearce (1979) and Thornton and Batten (1985). ${ }^{8}$ In addition, the orders chosen for $A(L)$ and $D(L)$ will be important for causal inferences as well. Recall that lagged values of the dependent variables are used to correct the serial correlation precipitated by an autocorrelated dependent variable. Because hypothesis tests are sensitive to the presence of significant serial correlation, biased causal inferences will result if incorrect orders for $A(L)$ and $D(L)$ are specified and employed in carrying out the test. Further discussion of the orders that were chosen for the four one-sided lag polynomials is provided in the next section.

Before turning to a discussion of the results of the test, a brief discussion of the data is warranted. Two measures of inflation, were considered and these included

${ }^{6}$ Because of certain identification problems inherent in determining the existence of instantaneouss causality, this paper uses only the notion of strict causality in carrying out the Granger test: see Pierce and Haugh (1979) and Price (1979). By definition, strict causality involves the past causing the present and the future, whereas, instantaneous causality involves the present causing the present. Because strict causality is being tested in this paper, no contemporaneous terms are included in the one-sided lag polynomials $A(L), B(L), C(L)$, and $D(L)$.

The assumption that the error terms $u$ and $v$ are individually and mutually uncorrelated means that the two equations in (2.1) can be estimated individually, using ordinary least squares (OLS).

${ }^{8}$ As is well known, there exists an important trade-off between bias and efficiency in the estimation of distributed lag models. In those models where excessively long lags are used, the problem of bias is avoided but at the cost of a decrease in the efficiency of estimates. On the other hand, lag lengths that are too short will produce efficient estimates that are biased if significant lags are omitted. This comment pertains to the estimation of distributed lag models and does not refer to biased efficient estimates. 
percentage changes in consumer prices (12 major cities, all goods) and wholesale prices. Both consumer and wholesale prices were measured as an index with 1980 as the base year. The percentage change in money supply was measured alternatively using the $M_{1}$ definition (i.e. currency outside banks and private-sector demand deposits) and the $M_{2}$ definition of money supply ( $M_{1}$ plus quasi-money, which consists of time, savings, and foreign currency deposits of residents). Both money measures were expressed in billions of current rupees. All data were measured monthly, were seasonally unadjusted, and were obtained from the IMF's International Financial Statistics. ${ }^{9}$ Percentage changes were computed as the unweighted first differences of the natural logarithm of the various series in successive time periods.

With specific regard to the two price indices used, a couple of comments are in order concerning differences between the CPI and WPI which could influence the results of the tests reported below. Firstly, the wholesale price index includes wholesale prices for food, raw materials, fuel, lighting, lubricants, and manufactures. The consumer price index is based on the retail prices confronted by a sample of industrial, commercial, and government employees in the twelve major cities of Pakistan. Because the twelve cities account for only 20 percent of the population, it appears that WPI is probably a better indicator of movements in the general price level than CPI. Secondly, price controls have existed on major commodities at the retail level for quite some time, making CPI less responsive to changing economic conditions than WPI.

Figures 1 and 2 plot the two general price levels, CPI and WPI, and the two money supply measures, $M_{1}$ and $M_{2}$, over the 1973-1985 period. All series are measured as levels. Figure 1 displays the movement in CPI and $M_{1}$ and $M_{2}$, while Figure 2 shows the movement in WPI and $\mathrm{M}_{1}$ and $\mathrm{M}_{2}$. Each of the four series displays an upward trend during the period. In addition, it is of interest to note how closely related the movements appear to be for the two price measures and the two money-supply measures over the sample period. The Granger test should thus provide some insight into the manner in which the money supply and price series are related over the $1973-1985$ period.

${ }^{9}$ The raw data were seasonally unadjusted in order to avoid problems inherent in using data that are seasonally adjusted by government agencies. Wallis (1974) has shown that the variou prothing observations on time series to remove the seasonal component can result in a distortion of the information content of the data, making valid causal inferences difficult. This is particularly a problem when time of the data, making valid causal inferences difficult. This is particularly a problem when time series are used which have been seasonally adjusted by different agencies using different seasonal adjustment the same seasonal adjustment procedure dat in the reasonal could be used in the series must be removed in carrying out the Granger test in order to avoid possible biases in the results that seasonality could precipitate. 


\section{EMPIRICAL RESULTS}

In order to assess the causal relationship between money supply and prices in Pakistan over the period from 1973 to 1985 , the individual equations of (2.1) were estimated using ordinary least squares (OLS). ${ }^{10}$ In order to remove deterministic seasonal and remaining non-stationary elements, each of the money growth and inflation series was first regressed on a linear trend and seasonal dummies. ${ }^{11}$ The residuals from these regressions were then used in estimating the individual equations of (2.1) in both restricted and unrestricted forms in carrying out the Granger test.

The causality tests undertaken here are only bivariate in nature and therefore exclude additional variables that may have explanatory power for both inflation and money growth. For example, although it is true that money is not the only factor affecting prices, we wanted to see whether money has any role to play in explaining inflation in the light of the recent debate in Pakistan that government deficits cause changes in money supply, which in turn cause inflation. Clearly, additional factors such as foreign inflation and supply shocks do also contribute to inflation. An important extension of the work done in this paper would be to use multivariate causality tests to assess the impact of these additional factors on domestic inflation in Pakistan.

The following lag lengths for the one-sided lag polynomials $A(L), B(L), C(L)$, and $D(L)$ were used in implementing the test. First, the order of both $A(L)$ and $D(L)$, the lag polynomials associated with the dependent variables in the equations estimated, was set at 12 . Because the data are monthly, it was felt that the use of 12 lagged values of the dependent variable as RHS variables was adequate to make adjustment for the autocorrelation pattern in the dependent variable that would otherwise be picked up by the regression residuals: see Nelson (1973). The use of lagged values of the dependent variable as RHS variables represents a fairly standard approach to correct serial correlation that would be caused by an autocorrelated dependent variable: see Granger and Newbold (1974). ${ }^{12}$

${ }^{10}$ The sample period begins in 1973 and not earlier in order to avoid any problems with data that might arise from including the pre-1973 period during which Bangladesh was a part of Pakistan.

${ }^{11}$ One of the referees pointed out that the use of percentage changes was sufficient to assure stationarity of the data. While in general this may prove to be true, there was still some evidence of a trend in the percentage changes for which an adjustment had to be made.

${ }^{12}$ One of the referees suggested that the lag lengths for both the dependent and independent variables be the same. We chose not to do this for a couple of reasons. Firstly, degrees of freedom would be quickly exhausted leading to less powerful tests when longer lags are used. Secondly, the use of 12 lagged values of the dependent variable as RHS variables were sufficient to correct serial correlation brought about by an autocorrelated dependent variable. The Qstatistics from all the equations estimated revealed that all the residuals were white noise at traditional confidence levels, suggesting that longer lag lengths on the dependent variable were unnecessary. In modelling the autocorrelation structure of a monthly time-series in order to remove the autocorrelation from the series, it is standard to examine lags of 12 months in order to discern any pattern that may exist in the series: see Nelson (1973). 


\section{EMPIRICAL RESULTS}

In order to assess the causal relationship between money supply and prices in Pakistan over the period from 1973 to 1985 , the individual equations of (2.1) were estimated using ordinary least squares (OLS). ${ }^{10}$ In order to remove deterministic seasonal and remaining non-stationary elements, each of the money growth and inflation series was first regressed on a linear trend and seasonal dummies. ${ }^{11}$ The residuals from these regressions were then used in estimating the individual equations of (2.1) in both restricted and unrestricted forms in carrying out the Granger test.

The causality tests undertaken here are only bivariate in nature and therefore exclude additional variables that may have explanatory power for both inflation and money growth. For example, although it is true that money is not the only factor affecting prices, we wanted to see whether money has any role to play in explaining inflation in the light of the recent debate in Pakistan that government deficits cause changes in money supply, which in turn cause inflation. Clearly, additional factors such as foreign inflation and supply shocks do also contribute to inflation. An important extension of the work done in this paper would be to use multivariate causality tests to assess the impact of these additional factors on domestic inflation in Pakistan.

The following lag lengths for the one-sided lag polynomials $A(L), B(L), C(L)$, and $D(L)$ were used in implementing the test. First, the order of both $A(L)$ and $D(L)$, the lag polynomials associated with the dependent variables in the equations estimated, was set at 12 . Because the data are monthly, it was felt that the use of 12 lagged values of the dependent variable as RHS variables was adequate to make adjustment for the autocorrelation pattern in the dependent variable that would otherwise be picked up by the regression residuals: see Nelson (1973). The use of lagged values of the dependent variable as RHS variables represents a fairly standard approach to correct serial correlation that would be caused by an autocorrelated dependent variable: see Granger and Newbold (1974). ${ }^{12}$

${ }^{10}$ The sample period begins in 1973 and not earlier in order to avoid any problems with data that might arise from including the pre-1973 period during which Bangladesh was a part of Pakistan.

${ }^{11}$ One of the referees pointed out that the use of percentage changes was sufficient to assure stationarity of the data. While in general this may prove to be true, there was still some evidence of a trend in the percentage changes for which an adjustment had to be made.

${ }^{12}$ One of the referees suggested that the lag lengths for both the dependent and independent variables be the same. We chose not to do this for a couple of reasons. Firstly, degrees of freedom would be quickly exhausted leading to less powerful tests when longer lags are used. Secondly, the use of 12 lagged values of the dependent variable as RHS variables were sufficient to correct serial correlation brought about by an autocorrelated dependent variable. The Qstatistics from all the equations estimated revealed that all the residuals were white noise at traditional confidence levels, suggesting that longer lag lengths on the dependent variable were unnecessary. In modelling the autocorrelation structure of a monthly time-series in order to remove the autocorrelation from the series, it is standard to examine lags of 12 months in order to discern any pattern that may exist in the series: see Nelson (1973). 
Then the orders for $B(L)$ and $C(L)$ were set alternatively at 12,24 , and 36 in order to allow for the impact of the independent variable on the dependent variable over a varying period of time. In a recent study, Thornton and Batten (1985) found evidence which suggested that an extensive search of the lag space should be conducted in carrying out the Granger test. In particular, it is important to experiment with alternative lag-lengths for the $B(L)$ and $C(L)$ lag polynomials so as to avoid omitting significant lagged values of the independent variables that would bias the F-statistics used in drawing causal inferences.

Tables 1 and 2 report the OLS results of the Granger test. Table 1 reports the computed F-statistics for testing the null hypothesis that money growth does not cause changes in the price level. Table 2 reports the computed F-statistics for testing the null hypothesis that movements in the price level have no impact on money growth. In both tables, results are presented for the three alternative lag-lengths of 12,24 , and 36 months on the independent variable.

Table 1

Empirical Results of Granger Test (12, 24, and 36 Lags on Money Growth)

\begin{tabular}{lrc}
\hline Regression & Computed F-Statistic & Significance \\
\hline A. 12 Lags on Money Growth & 1.56 & \\
CPI on M1 & .89 & NS \\
WPI on M1 & .99 & NS \\
CPI on M2 & 1.37 & NS \\
WPI on M2 & & NS \\
& & \\
B. 24. Lags on Money Growth & .97 & NS \\
CPI on M1 & 1.21 & NS \\
WPI on M1 & .97 & NS \\
CPI on M2 & 1.60 & $5 \%$ \\
WPI on M2 & & \\
& & \\
C. 36 Lags on Money Growth & 1.02 & NS \\
CPI on M1 & 1.70 & $5 \%$ \\
WPI on M1 & 1.02 & NS \\
CPI on M2 & 1.81 & $1 \%$ \\
WPI on M2 &
\end{tabular}

Notes: (a) The residuals from all equations estimated were non-autocorrelated at the 95 -percent confidence level according to Box-Pierce Q-statistics.

(b) NS denotes not significant at the 5-percent level or better.
Table 2

Empirical Results of Granger Test

(12, 24, and 36 Lags on Inflation)

\begin{tabular}{ccc}
\hline \multicolumn{1}{c}{$(12,24$, and 36 Lags on Inflation) } \\
\hline Regression \\
\hline
\end{tabular}

A. 12 Lags on Inflation

$\begin{array}{lrr}\text { M1 on CPI } & 2.05 & 5 \% \\ \text { M1 on WPI } & .86 & \text { NS } \\ \text { M2 on CPI } & 3.16 & 1 \% \\ \text { M2 on WPI } & .53 & \text { NS }\end{array}$

B. 24 Lags on Inflation

$\begin{array}{lrr}\text { M1 on CPI } & 1.60 & 5 \% \\ \text { M1 on WPI } & .49 & \text { NS } \\ \text { M2 on CPI } & 1.38 & \text { NS } \\ \text { M2 on WPI } & .73 & \text { NS }\end{array}$

C. 36 Lags on Inflation

$\begin{array}{lrr}\text { M1 on CPI } & 1.35 & \text { NS } \\ \text { M1 on WPI } & .73 & \text { NS } \\ \text { M2 on CPI } & 1.16 & \text { NS } \\ \text { M2 on WPI } & .90 & \text { NS }\end{array}$

Notes: (a) The residuals from all equations estimated were non-autocorrelated at the 95 -percen confidence level according to Box-Pierce Q-statistics.

(b) NS denotes not significant at the 5-percent level or better.

The results in Table 1 show that money growth has a significant impact on in flation when lags of 24 and 36 months on money growth are considered. In particular, growth in $M_{2}$ is found to cause WPI at the 5-percent level when a lag of 24 months on $M_{2}$ is considered, while the WPI is caused by $M_{1}$ and $M_{2}$ at the 5- and 1 -percent levels respectively when a lag length of three years on money growth is used. There is no evidence of a causal relationship from changes in money supply to either measure of price inflation over a 12 -month horizon. Also, quite surprisingly, there is evidence that money growth affects WPI, but not CPI, over the 24 month and 36-month horizons. This result is perplexing, given the high degree of correlation between consumer and wholesale price indices. The only explanation that we can offer for the anomalous result - that movements in money supply fail to cause changes in consumer prices - involves (1) the fact that price controls have existed on major commodities at the retail level for quite some time, making CPI less responsive to movements in the money supply, and (2) the fact that CPI is not 
as broad a measure of the general price level as WPI. Both of these points were raised above in our discussion of the data.

The results in Table 2 reveal that movements in consumer prices cause $M_{1}$ and $M_{2}$ growth at the 5- and 1-percent levels respectively over a time horizon of twelve months. In addition, the percentage change in CPI is found to cause $M_{1}$ at the 5-percent level when a lag of two years on inflation is considered. There is no evidence of price changes affecting money growth over a 36-month horizon. Finally, it is interesting to note that movements in CPI, and not WPI, have a significant explanatory power for the growth of $M_{1}$ and $M_{2}$ over the sample period. As before, an explanation for the difference in the causal inferences across the two inflation measures must involve the differences between CPI and WPI discussed above.

\section{SUMMARY AND CONCLUSIONS}

This paper represents an initial attempt to examine the causal relationship between money growth and price changes for Pakistan. The period investigated extends from January 1973 to September 1985. In order to shed some light on the issue of whether growth in money supply affects price changes, this paper employed the Granger direct test to test the null hypothesis of a lack of causality from money growth to inflation. In addition, the Granger test was used to determine the presence of feedback from inflation to money growth over the $1973-1985$ period. Two measures of inflation were considered and included percentage changes in consumer prices and wholesale prices. Two alternative measures of growth in money supply were used, which included percentage changes in the $M_{1}$ and $M_{2}$ definitions of money supply.

The results of the test showed a significant causal relationship from both $M_{1}$ and $M_{2}$ to wholesale prices, but not to consumer prices. There was no indication of a feedback from wholesale prices to either money measure. In addition, the results revealed that movements in consumer prices, but not in wholesale prices, affected both $M_{1}$ and $M_{2}$ without any evidence of feedback from either $M_{1}$ or $M_{2}$ to consumer prices. An explanation for the difference in the causal inferences across the two inflation measures involves differences between CPI and WPI which make WPI a better overall measure of the general price level.

These results have important implications for the building of monetary block in macro-econometric models of Pakistan's economy. Firstly, the results indicate that either $M_{1}$ or $M_{2}$ can be used as one of the explanatory variables when wholesale prices are being modelled. This is not the case, however, when consumer prices are being modelled, since neither $M_{1}$ nor $M_{2}$ was found to have a significant explanatory power for consumer prices. Secondly, the evidence does not corroborate the hypothesis that monetization of government deficits has caused inflation in Pakistan when the consumer price index is used to measure price movements. Further research should be directed towards exploring the role played not only by both international factors and the services sector but also by supply shocks in explaining movements in CPI.

As far as policy considerations are concerned, the results of the Granger test suggest that policy-makers in Pakistan may exploit the causal relationship from money to wholesale prices in their attempts to control the price level. However, in keeping with the Lucas critique, the success of any such attempt by policy-makers to control the movement in WPI would be dependent upon whether the relationship between money and WPI remains invariant to policy intervention.

\section{REFERENCES}

Aghevli, B., and M. Khan (1978). "Government Deficits and the Inflationary Process in Developing Countries". International Monetary Fund Staff Papers. pp. 383-416.

Benderly, J., and B. Zwick (1985). "Money, Unemployment, and Inflation". Review of Economics and Statistics. Vol. 67. pp. 139-143.

Driscoll, M. J., J. L. Ford and A. W. Mullineux (1985). "The Elasticity of Prices with Respect to Monetary Components: Some Estimates for the U.K., 1948-1979'. Applied Economics. Vol. 17. pp. 95-106.

Feige, Edgar L., and Douglas K. Pearce (1979). "The Casual Causal Relationship Between Money and Income: Some Caveats for Time Series Analysis'. Review of Economics and Statistics. Vol. 47. pp. 521-533.

Geweke, John, Richard Meese and Warren Dent (1983). "Comparing Alternative Tests of Causality in Temporal Systems: Analytical Results and Experimental Evidence". Journal of Econometrics. Vol. 21. pp. 161-194.

Granger, C. W. J., and P. Newbold (1974). "Spurious Regression in Econometrics". Journal of Econometrics. Vol. 2. pp. 111-127.

Jones, J. D., and N. D. Uri (forthcoming 1987). "Money, Inflation, and Causality: Another Look at the Evidence for the U.S., 1953-1984". Applied Economics.

Khan, A. (1982). "The Demand for Money and the Variability of Inflation: An Empirical Note". Economics Letters. Vol. 10, pp. 257-261.

Khilji, N. (1982). "Growth Prospects of a Developing Economy: Pakistan”. Ph.D. dissertation, McMaster University.

Lucas, R. (1985). "Econometric Policy Evaluation: A Critique". Studies in Business-Cycle Theory. Cambridge, MA: The MIT Press. pp. 104-130.

Naqvi, Syed Nawab Haider, A. Khan, N. Khilji and Ather Maqsood (1983). The P.I.D.E. Macroeconometric Model of the Pakistan Economy. Islamabad: Pakistan Institute of Development Economics.

Pierce, D. A., and L. D. Haugh (1979). "The Characterization of Instantaneous Causality: A Comment". Journal of Econometrics. Vol. 10. pp. 257-259. 
Price, J. M. (1979). "The Characterization of Instantaneous Causality: A Correction". Journal of Econometrics. Vol. 10. pp. 253-256.

Sims, Christopher (1972). "Money, Income, and Causality". American Economic Review. Vol. 62. pp. 540-552.

Thornton, D. L., and D. S. Batten (1985). "Lag-Length Selection in Tests of Granger Causality Between Money and Income". Journal of Money, Credit, and Banking. Vol. 17. pp. 164-178.

Turnovsky, S., and M. Wohar (1984). "Monetarism and the Aggregate Economy: Some Longer Run Evidence". Review of Economics and Statistics. Vol. 66. pp. 619-629.

Wallis, K. F. (1974). "Seasonal Adjustment and Relations Between Variables". Journal of the American Statistical Association. Vol. 69. pp. 18-31. 